\title{
Correction to: Novel servo-feed-drive model considering cutting force and structural effects in milling to predict servo dynamic behaviors
}

\section{Chen-Jung $\mathrm{Li}^{1} \cdot$ Hsiang-Chun Tseng ${ }^{2} \cdot$ Meng-Shiun Tsai $^{3} \cdot$ Chih-Chun Cheng ${ }^{2}$}

Published online: 19 March 2020

(C) Springer-Verlag London Ltd., part of Springer Nature 2020

Correction to: The International Journal of Advanced Manufacturing Technology (2020) 106:1441-1451

https://doi.org/10.1007/s00170-019-04778-9

In the accepted paper, the authors' affiliation has been wrongly typeset as People's Republic of China, but this should read Taiwan. The correct affiliations are shown below.

The publisher apologize for this mistake.

The online version of the original article can be found at https://doi.org/ 10.1007/s00170-019-04778-9

Hsiang-Chun Tseng

imesjtzeng@gmail.com

1 Department of Mechatronics Engineering, National Kaohsiung University of Science and Technology, Kaohsiung City 824, Taiwan

2 Department of Mechanical Engineering, National Chung Cheng University, Chiayi County 621, Taiwan

3 Department of Mechanical Engineering, National Taiwan University, Taipei City 106, Taiwan 